\title{
A tale of two species: climate-competition tradeoffs shape range limits according to tree life-history strategies
}

\author{
Jonathan Schurman ${ }^{1}$, Pavel Janda ${ }^{1}$, Milos Rydval ${ }^{1}$, Martin Mikolas ${ }^{1}$, Miroslav Svoboda ${ }^{1}$, \\ and Flurin Babst ${ }^{2}$ \\ ${ }^{1}$ Czech University of Life Sciences Prague \\ ${ }^{2}$ The University of Arizona School of Natural Resources and the Environment
}

February 9, 2021

\begin{abstract}
Adapting for competitiveness versus climatic stress tolerance constitutes a primary trade-off differentiating tree life-history strategies. This tradeoff likely influences where species' range-limits occur, but such links are data-demanding to study and key mechanisms lack empirical support. Using an exceptionally rich dendroecological network, we assessed spatial variation in climate and competition effects on Picea abies and Fagus sylvatica throughout the Carpathian Ecoregion. Ring width synchrony aided in diagnosing how the prevalence of resource-limited (competition) and sink-limited (climate) growth changes with altitude and community composition. Contrasting growth patterns towards respective upper and lower range limits of Fagus and Picea reflected tradeoffs between competitive vs. cold-tolerant strategies. Fagus performance declined with altitudinal increases in climate sensitivity, but improved under interspecific competition. Picea growth increased towards the species' lower range limit, but declined under interspecific competition. Warmer temperatures likely benefit competitively stronger species at mid elevations and thus imply range reductions for alpine conifers.
\end{abstract}

\section{Introduction}

Climate stress and competition influence plant growth through different physiological pathways and vary inversely in importance along gradients of productivity and climatic harshness (e.g., Coomes and Allen 2007; Ettinger et al. 2011; Rollinson et al. 2016). Adapting for the unique challenges posed by competition or climate is thereby considered a fundamental tradeoff differentiating primary plant life-history strategies (i.e., strong competitors vs. stress tolerators; Grime 1977; Reich et al. 2003). In turn, the stress-tradeoff hypothesis explains compositional patterns along climatic gradients by arguing that the biogeographic range limits of these primary strategies reflect the poor performance of i) stress tolerant species under competitive suppression, and ii) competitive species under climatic stress (Louthan et al. 2015). However, despite broad acceptance of this foundational theory, observations confirming a role for the stress-tradeoff hypothesis in dictating species range limits - especially those of tree species - are surprisingly sparse (see Anderegg and HilleRisLambers 2019 and references therein). This shortage likely persists because additional ecological dimensions (e.g., population structure, community composition, natural disturbances) alter the interplay between climate sensitivity and competition in forests (Babst et al. 2018) and highlights outstanding complications in the reliable scaling of tree-level mechanisms to explain forest biogeography (Mori 2019).

Climate and competition impart unique spatiotemporal patterns on tree growth, which could aid in disentangling their respective influences throughout biogeographic regions. Climatic stress is relatively coherent across larger regions and varies interannually. This spatiotemporal character of climatic variability synchronizes the growth of trees co-occurring within macroclimatic envelopes-growth series from trees sharing common climatic drivers will demonstrate heightened correlation (Fig. 1; e.g., Shestakova et al. 2016; Schurman et al. 2019). Mechanistically, climatic stress acts as a direct constraint on wood synthesis by affecting 
the rate and duration of wood cell division, expansion and cell wall formation (Wardlaw 1990; Körner 2003). Growth under such constraints is commonly referred to as sink limited, (a term deriving from the role of woody tissues as a carbon sink).

In contrast to climate, competition is a localized constraint that operates within tree communities, and is considerably more stable and predictable over time (Fritts 1976; McDowell et al. 2020). Trees occurring in close proximity will compete for finite resources and larger trees will garner disproportionately more resources (Weiner 1990). The growth rates of trees with differential access to resources will diverge (unlike climate, which synchronizes tree growth) (Clark 2011). If resource acquisition fails to sustain the rates of wood synthesis permissible under ambient climatic conditions, then growth will be resource limited and likely decouple from climatic variability. For example, understory trees are generally less climate-sensitive than overstory cohorts (e.g., Teets et al. 2018; Saulnier et al. 2020), and less responsive to the alleviation of climate stress (e.g., boreal warming, Luo et al. 2020). The size-dependent impact of competition further suggests that the growth synchrony between overstory and understory tree cohorts will decline towards more benign growing conditions, as the growth of understory trees increasingly decouples from climate (see Fig 1.g-i).

The functional differences between deciduous angiosperms and evergreen conifers, especially regarding wood anatomy, provide a particularly clear example of tradeoffs between competitive and stress-tolerant life histories (e.g., Bond 1989; Brodrib et al. 2012). Whereas conifer xylem consists of a relatively homogeneous matrix of tracheids (slim water-conducting cells several millimeters in length), angiosperm wood contains more recently evolved vessels (wider water-conducting conduits potentially reaching meters in length). Vessels are substantially more efficient in water transport, allowing angiosperms to support high leaf area canopies (Tyree \& Ewers 1991) capable of intercepting large proportions of incoming light and bolstering the competitive proclivity of late-successional angiosperms (Bazzaz 1979). However, large diameter vessels are vulnerable to climatic hazards, such as frost- or drought-induced embolism, to which the more compartmentalized matrix of conifer wood is substantially more resistant (Sperry, Hacke, \& Pitterman 2006). This phylogenetic contrast highlights the appeal of the stress-tradeoff hypothesis as a concise explanation for emergent biogeographic patterns, where conifers persist under cold or arid climates and angiosperms dominate under benign temperate conditions (Bond 1989). However, despite this strong theoretical foundation, the role of angiosperm competition as a constraint on conifer distributions is not well grounded in actual field observations (Augusto et al. 2014).

Dendroecological studies have emerged as a robust tool to understand how competition (e.g., Teets et al. 2018; Saulnier et al. 2020), climate gradients (e.g., Primicia et al. 2015; Schurman et al. 2019; del Rio et al. 2020) and their interactions (Rollinson et al. 2016; Buechling et al. 2017) alter tree growth. Yet, the higher density of tree-ring sampling that is required for such spatially explicit studies has rarely been achieved at sufficiently large scales to empirically assess range-limit mechanisms (but see Anderegg and HilleResLambers 2019). In this respect, the present study constitutes a more than ten-fold increase in the number of tree-ring samples collected compared to conventional dendroecological studies of growth and range dynamics. This allowed us to quantify how the interplay between competition and climate sensitivity changes with variation in local forest structure and community composition, and along macroclimatic gradients (i.e., altitude and latitude) throughout a biogeographic region (Fig. 2). After confirming tree-growth synchrony as a reliable indicator of sink vs. resource-limited growth, we examined spatial patterns in synchrony and absolute growth rates to determine the importance of climate and interspecific competition as range constraints for a shade-tolerant angiosperm (Fagus sylvatica) and a frost-hardy conifer (Picea abies ) throughout a mid-latitude montane ecoregion (the Carpathian Mountains). We further demonstrate how competition and climate sensitivity interact with structural, compositional and historical factors likely to obfuscate climate and competition as range-limit mechanisms and scale to produce regional patterns in climate sensitivity and forest productivity.

\section{Materials and Methods:}

\subsection{Study sites:}


The Carpathian Mountains constitute one of Europe's most pristine forested ecoregions, where fragments of primary forest remain protected from harvesting by complex montane topography. The ecoregion is broadly classified as cool-humid, with mean mid-altitude (1000 m a.s.l.) annual temperatures of $4.5^{\circ} \mathrm{C}$ and precipitation of $1100 \mathrm{~mm}$ over the past half a century (Spinoni et al. 2015). Quantifying forest dynamics in the Carpathians is a primary objective of the REMOTE (REsearch MOntane Temperate) Forest network, an expanding dendroecological forest inventory project. The REMOTE inventory was initialized in 2010 as an effort to locate stands of primary forests in both protected areas and isolated unprotected localities throughout the mountain range. Sites were defined with the assistance of park managers and other local experts (www.remoteforests.org; Svoboda et al. 2014).

\subsection{Forest Inventory Methods}

REMOTE study sites are distributed along the latitudinal extent of the Carpathian Arc, and encompass a sizable altitudinal gradient (approximately 600-1700 a.s.l.). Once primary fragments were located, a contiguous internal study site (henceforth, stand), was delineated. Stands vary in size from 10 to 60 ha, though most stands are approximately 30 ha. Inventory plots were randomly distributed along the corners of a regular square-celled grid to ensure a stratified random design. For Picea stands, grid spacing was 1-2 ha cells, for Fagus, grid resolution was 10 ha. In total, the dataset consists of 5380.1 ha plots located in 38 Picea -dominated stands and 278 plots located in 21 Fagus -dominated fragments (Fig 2). Piceaconstitutes over $95 \%$ of the individuals in Picea -dominated stands, whereas Fagus constitutes approximately $75 \%$ of individuals in Fagus -dominated stands, with Abies alba, Acer psuedoplatanus and Picea abies contributing an additional $24 \%$.

Within inventory plots, all trees $>10 \mathrm{~cm}$ in diameter at breast height (dbh) were identified and mapped. During inventory, trees were assigned to one of two competition classes: individuals taller than mean canopy height were designated to the overstory category and individuals below mean canopy height were designated understory. Inventory data were used to estimate stem densities and basal areas. Importantly for our analysis, there are no strong geographic patterns in the stand structure, which could otherwise alter our interpretation of the drivers of growth variability, though it should be noted though that basal areas and stem densities were weakly positively correlated with elevation $(\mathrm{r}=.21$ and .15 , respectively).

\subsection{Tree core sampling and processing}

Following inventory, a sample of trees was selected for tree coring. InPicea plots, a subset of 25 trees per plot were selected for tree core extraction. If plots contained less than 25 trees, all trees were cored. In Fagus plots, all trees over $20 \mathrm{~cm}$ dbh were cored and 1 in 4 trees in the 10-20 cm dbh class were cored, and all trees within a central 5m-radius subplot were cored. One core was extracted from each tree at $1 \mathrm{~m}$ above ground level and on the upslope side of the trunk. Only trees with more than 20 years of data were used and only plots with 5 or more trees were included. This yielded a dataset comprising 22209 trees within 813 inventory plots.

Tree cores were air-dried, then mounted on wooden boards and sanded until annual growth rings were made clearly visible. Following this, samples were cross-dated visually using extreme growth years (Yamaguchi, 1991). Annual ring widths were then measured using a stereomicroscope and a Lintab sliding-stage measuring station in conjunction with TSAP-WinTM software (Rinntech, Heidelberg, Germany). Cross-dating was subsequently validated using the programs COFECHA (Holmes 1983) and CDendro (Larsson, 2015).

\subsection{Tree growth metrics}

\subsubsection{Ring-width indices and basal area increment}

Two different growth metrics were derived from each series of tree-ring width increments: detrended ringwidth indices (RWIs) and basal area increments (BAIs). RWIs are highly suitable to extract the influence of high frequency climatic variability on tree growth and exclude low-temporal frequency effects (e.g. competition, ontogeny). To produce RWIs, we modelled low-frequency growth variation using a Friedman's super smoother, with the smoothing span optimized via leave-one-out cross-validation (Friedman, 1984). After 
dividing the observed ring widths by the respective smoothed values, a first order autoregressive model was applied to remove temporal autocorrelation. Tree-level RWIs of specific years can be averaged over different spatial scales to produce tree growth chronologies for specific spatial domains. Thus, we averaged over RWI series within inventory plots to produce plot-level RWI chronologies and plot chronologies were integrated to produce stand chronologies. Detrending and chronology building was entirely conducted using functions in the R package dplR (Bunn, 2008).

RWIs help disentangle various components of tree-growth variation, but as unitless indicators of relative tree growth, they cannot be interpreted in terms of actual quantities of wood produced per year. BAI provides a more direct representation of net wood synthesis (West, 1980). Because our extensive and representative sampling incorporated different tree sizes and competitive statuses, the BAI chronologies produced in our analysis provide an accurate image of spatial variation in forest-level wood production. BAIs are estimated from radial growth increments, by converting these increments into cross sectional areas and subtracting the cross-sectional areas between adjacent years:

$\mathrm{BAI}_{\mathrm{t}}=\pi^{*}\left(\mathrm{D}_{\mathrm{t}} / 2\right)^{2}-\pi^{*}\left(\mathrm{D}_{\mathrm{t}-1} / 2\right)^{2}$

Where $D_{t}$ is the reconstructed tree diameter in a specified year, and $D_{t-1}$ is the diameter of the previous year. Diameters were adjusted by a coefficient to account for any potential asymmetry in ring geometry: Ring widths are divided by the length of the corresponding increment core to produce proportional diameters, which are subsequently multiplied by the measured dbh of the tree. If a given core did not include the pith, but came within $10 \mathrm{~mm}$, then the distance to the missing pith was estimated from the arcs of the inner rings (Duncan 1989). Cores which missed the pith by more than $10 \mathrm{~mm}$ were excluded from analyses involving BAI.

\subsubsection{Synchrony estimation}

We employed two methods to estimate growth synchrony, one to estimate intraspecific variation in climate sensitivity of individual trees, the second to estimate the climate sensitivity of whole assemblages.

Tree-level growth synchrony was estimated by calculating the Pearson's correlation coefficient correlating between the RWI series of individual trees with the species-specific RWI chronology of their corresponding stand. This was done for the two most abundance species in the Carpathians, $P$. abies and $F$. sylvatica.These correlation coefficients were used as direct estimators of tree-level growth synchrony for all tree-level analyses.

We derived a second synchrony metric to provide point estimates of growth synchrony that integrate structural and compositional variability. To do so, we estimated the correlation among the RWI series of all overstory trees, regardless of species, co-occurring within forest inventory plots and averaged over these correlation coefficients to estimate the mean interseries correlation $(r)$ for each inventory plot. By restricting this second synchrony metric exclusively to individuals from the overstory competition category, analyses better reflect relationships between synchrony and forest productivity. The overstory competition class comprised over $90 \%$ of forest basal area, thus our estimates of $r$ are not influenced by abundant understory trees that contribute marginally to forest biomass production, but could greatly influence $r$ estimates.

\subsubsection{Disturbance history}

These data have previously been used to reconstruct disturbance histories throughout the Carpathians (for details, see Svoboda et al 2014; Schurman et al. 2018). In brief, tree growth series are scanned for decadalscale growth rate anomalies indicative of the rapid reductions in competition that occur following disturbance. Gap sizes created by the historical event are inferred from the present canopy area of the released individual. Thus, if multiple co-occurring individuals were released during the same year, then their collective canopy areas are summed to estimate the gap fraction created by the disturbance event in a given year. For the present analysis, we extracted four disturbance history variables for each plot: the severity and time elapsed since each inventory plot's most severe disturbance (used in our longer-term analysis of synchrony) and the severity and time elapsed since each inventory plot's most recent disturbance (used in our analysis of near-term mean BAIs). 


\subsection{Statistical Analyses}

\subsubsection{Bivariate growth pattern analyses}

Our primary objective was to determine how variation in tree growth rates and climate sensitivity changes with altitude and with the species composition of neighboring trees. We began our analysis by conducting correlation tests to estimate the responsiveness of tree-level growth synchronies and log-transformed BAI for both Picea andFagus to elevation and neighborhood species composition. Mean BAIs were estimated over a recent time window that is common to all trees (c. 1980-2010) to minimize the potential impact of unobserved changes in local forest structure on individual tree growth (Buechling et al. 2017). To understand the importance of competition, and to disentangle the importance of intraspecific vs. interspecific competition, we narrowed the scope of this analysis to the altitudinal range where Picea and Fagus overlap $(900 \mathrm{~m}$ to $1300 \mathrm{~m})$. We then again conducted correlation tests to quantify relationships between species diversity (using Shannon's diversity index; $\mathrm{H}=-\operatorname{sum}\left[\mathrm{pi} * \log \left(\mathrm{p}_{\mathrm{i}}\right)\right]$ ), $\log (\mathrm{BAI})$ and synchrony.

\subsubsection{Multivariate analysis of BAI and tree synchrony: tree size, community and geographic effects}

Following bivariate analyses, we fit a more comprehensive set of multivariate models to better assess the relative importance of geographic and structural/compositional factors as determinants of tree growth patterns. Tree-level models were fit separately for Piceaand Fagus. Both tree-level interseries correlations and mean BAI over the 1980-2010 interval were modeled as a function of canopy status, species diversity, altitude and latitude. For BAI models, growth synchrony was included as an additional explanatory factor. Tree synchrony was additionally integrated into models explaining variation in $\log (\mathrm{BAI})$. Effect sizes for altitude, latitude, diversity and synchrony were allowed to vary with competition class. All variables were standardized to a mean of zero and a standard deviation of 1 . The fact that trees co-occurring within close proximity cannot be considered independent samples complicated the interpretation of this analysis. Mixed effect models allowed us to simultaneously estimate the effects of several explanatory factors while simultaneously fitting random effects to control for the potential autocorrelation among co-occurring trees. Using mixed effects models allowed us to fit a random intercept for each plot and nest our effect size estimates within tree competition classes:

Synchrony $=\beta_{0 \mathrm{i}}+\beta_{1 \mathrm{j}} *$ Elevation $+\beta_{2 \mathrm{j}} *$ Latitude $+\beta_{2 \mathrm{j}} *$ Diversity $+\varepsilon_{\mathrm{k}}$

$\log (\mathrm{BAI})=\beta_{0 \mathrm{i}}+\beta_{1 \mathrm{j}} *$ Elevation $+\beta_{2 \mathrm{j}} *$ Latitude $+\beta_{2 \mathrm{j}} *$ Diversity $+\beta 3_{\mathrm{j}} *$ Synchrony $+\varepsilon_{\mathrm{k}}$,

where, $\beta_{0 \mathrm{i}}$ are random intercepts for each of $i$ plots, and $\beta_{\mathrm{nj}}$ are effect size estimates, nested within the $j=2$ canopy classes, and $\varepsilon_{\mathrm{k}}$ is a randomly distributed error term for each of $k$ trees.

\subsubsection{Multiple regression on regional variation inr and mean BAI}

Multiple regressions were conducted to test the relative importance of abiotic vs. biotic factors in driving regional growth patterns that integrated all local variability in tree growth (averaging over species and competition classes). All variables were standardized to a mean of zero and a standard deviation of one prior to analysis. Response variables included $r$ and mean BAI over 1980-2010. Importantly, $r$ was also used as an explanatory factor in the model predicting BAI.

Abiotic factors included altitude and latitude. Structural factors included stem densities and plot-level basal area. The effect of species composition was incorporated, again using Shannon's diversity index. Disturbance variables were also included. The time since the most recent disturbance and the severity of the most recent disturbance was included in the model of mean BAI, and the time since and severity of each plot's most severe disturbance was incorporated into our model of $r$.

\section{Results}

\subsection{Tree level synchrony and growth}

Bivariate relationships demonstrated the strength of the correlation between growth synchrony and BAIs. Growth synchrony generally increased with altitude and BAI declined with altitude. Fagus growth synchrony 
and BAI also increased with species diversity. By contrast, Picea growth synchrony declined with species diversity and BAI of understory Picea trees was prominently negatively correlated with species diversity. See figure 3 for correlation estimates.

We integrated these results into regression models of growth synchrony and BAIs (all effect sizes reported in table 1). For both species, diameter was a prominent determinant of both ring-width synchrony and BAI, though stronger for BAI. In general, effect sizes of biotic and abiotic factors were stronger for synchrony than BAI. Understory synchrony was lower for both species. Elevation has a positive effect on growth synchrony for both species and all competition classes, though this effect was strongest for understory Fagus. BAI declined significantly with elevation except for understory Picea, which was non-significant. The positive effect of elevation on growth synchrony was apparent for beech and similar for both canopy classes. For spruce, elevation effects were larger for overstory trees than for understory individuals. Understory beech appear to increase greatly in ring-width synchrony as species diversity in the canopy increases. Species diversity had a positive effect on Fagus synchrony and a negative effect on Piceasynchrony. Understory Picea had the strongest BAI response to species diversity, which was negative.

\subsection{Spatial variation in $r$ and mean $B A I$}

The mean $r$ among overstory trees within inventory plots was 0.309 , with a standard deviation of 0.089. Multiple regression indicated that geographic factors (elevation and latitude), structural composition (stem density and basal area) and species composition collectively explain an appreciably high degree of the spatial variation in $r\left(\mathrm{r}^{2}=0.59\right)$, and therefore indicated where forest productivity is most tightly coupled to climate. Climate sensitivity increased prominently with elevation (Standardized effect size $=0.42$ ) and latitude (SEF $=0.26)$. We also detected a positive interaction between elevation and latitude (0.150), suggesting that elevation effects increase with latitude. The effect of species diversity was similar in magnitude to elevation, but opposite in sign (-0.43) implying that ring-width synchrony declines with species diversity. Stem densities have a negative effect on $r$ while the effect of basal area was positive.

The same ecological factors, with the addition of $r$ were fit to the variation in mean BAI c. 1980-2010 $\left(\mathrm{r}^{2}\right.$ $=0.364)$. Elevation and its interaction with latitude was the primary constraining factor, followed by the negative effects of stem densities (0.-29) and $r(-0.27)$. Plot-level basal area was positively correlated with mean BAI (0.202). Species diversity did not have a significant effect on mean BAI (Table 2).

\section{Discussion}

This study empirically assessed the transition between climate-limited and competition-dominated tree growth across a large geographic and bioclimatic space. Clear patterns emerged that suggest a key role for altitudinal temperature gradients in regulating the relative importance of sink limitation vs. resource availability as constraints on tree growth and species' ranges throughout a mid-latitude temperate montane ecoregion. Growth patterns towards the range limits of our two focal species aligned with our understanding of these species as representatives of two primary life-history strategies (sensuGrime 1977), with climatic stress setting the upper altitudinal limit of a shade-tolerant angiosperm (Fagus sylvativa) and interspecific competition setting the lower distributional limit of a frost-hardy conifer (Picea abies). These findings reinforce important roles for tradeoffs among primary life history strategies and the stress-gradient hypothesis (Anderegg and HilleRisLambers 2019) as explanations for the ecological gradients that are typically encountered along temperate-to-alpine conditions (Schimper 1898).

\section{Competition reduces growth synchrony}

The pronounced positive effect of altitude on tree growth synchrony and its negative effect on basal area increments (BAI) (paired with altitudinal increases in sensitivity to summer temperature and winter precipitation; supplementary information 1), strongly suggests increased sink limitation towards harsher alpine conditions and the alleviation of climatic constraints at low altitudes. If climatic stress declines, then other factors necessarily increase in importance as wood synthesis constraints (Bloom, Chapin \& Mooney, 1985). The observed decline in growth synchrony towards lower altitudes was more rapid for understory trees com- 
pared to overstory trees, especially for $F$.sylvatica, reflecting how the characteristically lower climatic sensitivity of competitively inferior trees emerges with improved growing conditions (Teets et al. 2018, Luo et al. 2020). Similarly, we detected a positive association between growth synchrony and BAI among lowaltitude trees, implying that trees coupled to climate variation (i.e. overstory trees) grow at rates closer to their physiological maximum and that competition inhibits the realization of sink-limited growth. Observing this disparity in climate sensitivity between competition classes, combined with the declining climate stress towards lower altitudes, strongly suggests that competition-driven resource limitation replaces sink limitation as growing conditions improve.

\section{Competition and climate dictate range limits of Picea and Fagus, respectively}

The processes regulating tree performance at their respective upper and lower range limits differed for $F$. sylvatica and $P$.abies. In the Carpathians, the growth rate of $F$.sylvatica declines as growth synchrony increases towards its upper elevation limit, which is highly indicative of a species growing at the limit of its climatic tolerance (Jump et al. 2006). Aspects of xylem anatomy related to hydraulic conductivity are closely associated with the upper altitudinal limits of most European tree species, including $F$. sylvatica, with large vessels amplifying the risks of embolism formation under freezing and thawing cycles (Charrier et al. 2013). The capacity of $F$. sylvatica to repair cavitation is temperature sensitive (Cochard et al. 2001), similarly reflected in the heightened sensitivity of $F$. sylvatica to winter temperatures in the Carpathians (Supporting Info 1) and towards $F$. sylvatica 's northern distribution (Weigel et al. 2018), which almost certainly prevents this species from reaching dominant/mature size classes at high altitudes in the Carpathians.

Unlike $F$. sylvatica, the maximum growth rates of $P$.abies increased as its abundance declined towards its lower altitudinal limit; this misalignment between abundance and growth optimum strongly suggests that $P$ . abies is outcompeted at sites that offer more favorable growing conditions (Canham et al. 2004). Species composition had fundamentally different impacts on the growth patterns of $F$. sylvatica and $P$. abies within the overlapping segments of their altitudinal distributions, especially for understory trees. Understory $F$. sylvatica grew faster and in greater synchrony with climate under interspecific competition, implying an alleviation of competitive suppression. The opposite was true for $P$. abies, which exhibited lower growth rates and growth synchrony under mixed-species canopies. These patterns reinforce the notion of shade tolerant angiosperms as species that rise in abundance through monopolization of resources, namely light (Bazzaz 1979), and the competitive advantages afforded to angiosperms by their improved conductivity, higher leaf area, and faster growth (Bond et al. 1987).

\section{Structural, compositional, and historical factors alter tree-to-region scaling}

The shifting prevalence between resource and sink limitation along our temperate-to-alpine gradient interacts with an array of additional locally-variable factors, altering how tree-level constraints scale to regional productivity. At this broader scale, a negative association emerges between mean synchrony and mean BAI, implying a net reduction in forest productivity with increased climate stress. Stem density negatively influenced both BAI and synchrony, further implying that distributing resources over more individuals reduces growth and climate responsiveness. The detected positive associations between basal area, BAI and synchrony imply heightened productivity in plots with a larger proportion of dominant stems, and may further reflect the tendency for density-dependent processes to thin stands as dominant trees increase in size, reducing competitive interactions (Després et al. 2017). Similarly, growth synchrony increases with the severity of each location's maximum disturbance and time since this most extreme event, suggesting that more developmentally advanced forests have thinned intensely interacting trees, and mean BAI was higher in more recently and more severely disturbed plots.

Species diversity had a negative effect on plot-level growth synchrony, reflecting how species with different niches diverge in their responses to seasonal climate variability (e.g., Jucker et al. 2016, del Rio et al. 2020). Thus, diversity likely buffers forest productivity against stressful climate extremes. However, even though mixing Picea andFagus in plantations can often lead to positive diversity effects via complementarity (Pretzsch et al. 2010), niche differences in climate sensitivity did not translate into an apparent effect of 
diversity on mean growth at our Carpathian sites. Throughout Europe, positive diversity-productivity effects emerge on the most climatically stressful locations, with weakly negative diversity effects previously detected in temperate Carpathian forests (Jucker et al. 2016). In the Carpathians, the most diverse plots occur at the range limits of the two most abundant species, where competitive suppression of Picea is especially pronounced and Fagus is rather climatically stressed, highlighting the importance of considering underlying assembly processes when estimating diversity effects (Mori et al. 2018).

\section{Regional Implications: timber yield and conservation concerns}

Our results imply that the composition of mid-altitude, monospecific spruce forests will become increasingly mixed over the coming decades under rapid high-altitude warming (Beniston, Diaz and Bradley 1997).P . abies comprises the majority of roundwood timber supply in many European countries, with population sizes bolstered by continental reforestation efforts since the 1950s and a longstanding preference for Picea lumber over products from mixed-deciduous forests (Fanta 1997). Picea is increasingly regarded as an unsustainable timber-species choice, due to high drought susceptibility and worsening spruce beetle outbreaks (Hanewinkel et al. 2013). In these cool-humid Carpathian Picea forests, moisture sensitivity is somewhat higher in southern locations, but the majority of these sites have actually increased in productivity over 1980-2010 (Schurman et al. 2019). However, our results imply that managers in the region wishing to maintain monospecific Picea stands will battle against improved growing conditions for species like Fagus sylvatica that are likely to outcompete Picea .

The Carpathians are among Europe's most ecologically pristine ecoregions. In fact, sampling within fragments of primary forest throughout the Carpathians provided the rare opportunity to study a naturally occurring low-altitude range limit of Picea abies in Europe, where intense management has otherwise led to an artificial proliferation of Picea at low altitudes. The unique structural characteristics of these monospecific Picea forests, for example, disturbance patches generated by spruce beetle outbreaks, are crucial habitat elements for multiple species of high conservation value (Mikolaš et al. 2017). Critically, alpine areas conducive to monospecific Picea forests are shrinking, and the likely encroachment of low altitude tree species implies major changes to the variety of habitats found in these forests (Dirnböck et al. 2011). Determining whether species associated with monospecific spruce forests can adapt to forthcoming changes in forest composition emerges as a critical conservation priority.

\section{Conclusions:}

Analysis of growth synchrony patterns using comprehensive tree-ring data continues to provide deep insight into climate sensitivity (e.g., Shestakova et al. 2016, Anderegg and HilleRisLambers 2019, del Rio et al. 2020) and forest productivity (Schurman et al. 2019). In the present study, large sample sizes were necessary to accurately portray the sizable extent of variation among trees, both locally and across large geographic space. Such variability could certainly contribute to the inconsistency reported by some studies in demonstrating the importance of competition as a driver of species ranges (see Anderegg and HilleRisLambers 2019 and references therein). Pairing synchrony assessments with intensified sampling allowed us to robustly link highlevel biogeographic patterns to their lower-level mechanisms, namely how individual trees respond to climate and competition.

Growing season temperature is perhaps the most widely recognized climatic driver of forest productivity and species composition globally. In our analysis of a classic temperate-to-alpine forest transition, which likely mimics temperate-to-boreal gradients at even larger scales, we demonstrate how the manifold processes underlying tree growth change along a temperature gradient to alter species composition. Towards colder sites, slow growing trees are less likely to encounter resource limitation and competitive traits are likely maladaptive. As growing conditions improve, only competitively advantaged trees will grow at rates close to potential sink-limited maxima and species that cannot endure resource scarcity will struggle to sustain baseline metabolic requirements. Rather than thinking about competition and climate as direct constraints on tree performance, we highlight the importance of considering growth as an emergent property of both sink limitation and resource limitation, two independent processes with unique constraints. In our study, 
interspecific variation in tolerance of resource and sink limitation constituted the primary mechanism underlying the range limits of two contrasting life strategies, and will certainly dictate how the distributions of these two species respond to forthcoming climate change.

\section{Acknowledgements:}

The REMOTE primary forest network would not be possible without the work of dozens of dedicated field technicians and logistical support from local experts. We are also extremely grateful to D. Storch for providing insightful feedback on a later draft of our manuscript. Funding was provided by: EVA4.0: CZ.02.1.01/0.0/0.0/16_019/0000803 and the Czech Science Foundation project REPLICATE

(grant nr. 20-22351Y).

\section{References:}

1. Anderegg, L.D. \& HilleRisLambers, J. (2019). Local range boundaries vs. large-scale trade-offs: Climatic and competitive constraints on tree growth. Ecol. Lett. , 22, 787-796.

2. Augusto, L., Davies, T.J., Delzon, S. \& De Schrijver, A. (2014). The enigma of the rise of angiosperms: can we untie the knot? Ecol. Lett. , 17, 1326-1338.

3. Babst, F., Bodesheim, P., Charney, N., Friend, A.D., Girardin, M.P., Klesse, S. et al. (2018). When tree rings go global: Challenges and opportunities for retro-and prospective insight. Quat. Sci. Rev. , 197, 1-20.

4. Bazzaz, F.A. (1979). The physiological ecology of plant succession. Annu. Rev. Ecol. Syst. , 10, 351-371.

5. Beniston, M., Diaz, H.F. \& Bradley, R.S. (1997). Climatic change at high elevation sites: an overview. Clim. Change, 36, 233-251.

6. Bloom, A.J., Chapin III, F.S. \& Mooney, H.A. (1985). Resource limitation in plants-an economic analogy. Annu. Rev. Ecol. Syst., 16, 363-392.

7. Bond, W.J. (1989). The tortoise and the hare: ecology of angiosperm dominance and gymnosperm persistence. Biol. J. Linn. Soc., 36, 227-249.

8. Brodribb, T.J., Pittermann, J. \& Coomes, D.A. (2012). Elegance versus speed: examining the competition between conifer and angiosperm trees. Int. J. Plant Sci. , 173, 673-694.

9. Buechling, A., Martin, P.H., \& Canham, C.D. (2017). Climate and competition effects on tree growth in Rocky Mountain forests. J. Ecol. , 105, 1636-1647.

10. Bunn, A.G. (2008). A dendrochronology program library in R (dplR). Dendrochronologia, 26, 115-124.

11. Canham, C.D., LePage, P.T. \& Coates, K.D. (2004). A neighborhood analysis of canopy tree competition: effects of shading versus crowding. Can. J. For. Res., 34, 778-787.

12. Charrier, G., Cochard, H. \& Ameglio, T. (2013). Evaluation of the impact of frost resistances on potential altitudinal limit of trees. Tree Physiol. , 33 , 891-902.

13. Clark, J.S., Bell, D.M., Hersh, M.H. \& Nichols, L. (2011). Climate change vulnerability of forest biodiversity: climate and competition tracking of demographic rates. Glob. Change Biol. , 17, 1834-1849.

14. Cochard, H., Lemoine, D., Ameglio, T. \& Granier, A. (2001). Mechanisms of xylem recovery from winter embolism in Fagus sylvatica. Tree Physiol. , 21, 27-33.

15. Coomes, D.A. \& Allen, R.B. (2007). Effects of size, competition and altitude on tree growth. J. Ecol., 95, 1084-1097.

16. del Rio, M., Vergarechea, M., Hilmers, T., Alday, J. G., Avdagić, A., Binderh, F., et al. (2020). Effects of elevation-dependent climate warming on intra-and inter-specific growth synchrony in mixed mountain forests. For . Ecol . Manag ., 479, 118587. 
17. Després, T., Vítková, L., Bače, R., Čada, V., Janda, P., Mikoláš, M. et al. (2017). Past disturbances and intraspecific competition as drivers of spatial pattern in primary spruce forests. Ecosphere, 8, e02037.

18. Dirnböck, T., Essl, F. \& Rabitsch, W. (2011). Disproportional risk for habitat loss of high-altitude endemic species under climate change. Glob . Change Biol ., 17, 990-996.

19. Duncan, R.P. (1989) An evaluation of errors in tree age estimates based on increment cores in kahikatea (Dacrycarpus dacrydioides).New Zealand Natural Sciences , 16, 3 1-37.

20. Ettinger, A.K., Ford, K.R. \& HilleRisLambers, J. (2011). Climate determines upper, but not lower, altitudinal range limits of Pacific Northwest conifers. Ecology, 92, 1323-1331.

21. Fanta, J., 1997. Rehabilitating degraded forests in Central Europe into self-sustaining forest ecosystems. Ecol . Eng . 8, 289-297.

22. Friedman, J. H. (1984). A variable span smoother (No. LCS-TR-5). Stanford Univ CA lab for computational statistics.

23. Fritts, H. (1976). Tree rings and climate . Academic Press. London.

24. Grime, J.P. (1977). Evidence for the existence of three primary strategies in plants and its relevance to ecological and evolutionary theory. Am. Nat. , 111, 1169-1194.

25. Hanewinkel, M., Cullmann, D.A., Schelhaas, M.J., Nabuurs, G.J. \& Zimmermann, N.E. (2013). Climate change may cause severe loss in the economic value of European forest land. Nat . Clim .Change , 3, 203-207.

26. Holmes, R.L. (1983). Computer-assisted quality control in tree-ring dating and measurement. Tree-Ring Bulletin , 43, 69-78

27. Jucker, T., Avăcăriței, D., Bărnoaiea, I., Duduman, G., Bouriaud, O. \& Coomes, D.A. (2016). Climate modulates the effects of tree diversity on forest productivity. J. Ecol. , 104, 388-398.

28. Jump, A.S., Hunt, J.M. \& Penuelas, J. (2006). Rapid climate change-related growth decline at the southern range edge of Fagus sylvatica . Glob. Change Biol. , 12, 2163-2174.

29. Kahle, D. \& H. Wickham. (2013). ggmap: Spatial Visualization with ggplot2. The R Journal, 5, 144-161.

30. Körner, C. (2003). Carbon limitation in trees. J .Ecol ., 91, 4-17.

31. Larsson, L. (2015). CooRecorder and Cdendro Programs of the CooRecorder/Cdendro Package Version 7.8. Retrieved from http://www.cybis.se/forfun/dendro/

32. Louthan, A.M., Doak, D.F. \& Angert, A.L. (2015). Where and when do species interactions set range limits? Trends Ecol. Evo., 30, 780-792.

33. Luo, Y., McIntire, E.J., Boisvenue, C., Nikiema, P.P. \& Chen, H.Y. (2020). Climatic change only stimulated growth for trees under weak competition in central boreal forests. $J$.Ecol. , 108 , 36-46.

34. McDowell, N.G., Allen, C.D., Anderson-Teixeira, K., Aukema, B.H., Bond-Lamberty, B., Chini, L. et al. (2020). Pervasive shifts in forest dynamics in a changing world. Science, 368, 1-10.

35. Mikolaš, M., Svitok, M., Bollmann, K., Reif, J., Bace, R., Janda, P. et al. (2017). Mixed-severity natural disturbances promote the occurrence of an endangered umbrella species in primary forests. For. Ecol. Manag. , 405, 210-218.

36. Mori, A.S. (2018). Environmental controls on the causes and functional consequences of tree species diversity. J .Ecol ., 106, 113-125. 
37. Mori, A.S. (2019). Local and biogeographic determinants and stochasticity of tree population demography. J. Ecol. , 107, 1276-1287.

38. Nakagawa, S. \& Schielzeth, H. (2013). A general and simple method for obtaining R2 from generalized linear mixed-effects models. Methods Ecol. Evol. , 4, 133-142.

39. Pretzsch, H., Block, J., Dieler, J., Dong, P.H., Kohnle, U., Nagel, J. et al. (2010). Comparison between the productivity of pure and mixed stands of Norway spruce and European beech along an ecological gradient.Ann . For . Sci ., 67, 712-724.

40. Primicia, I., Camarero, J.J., Janda, P., Čada, V., Morrissey, R. C., Trotsiuk, V. et al. (2015). Age, competition, disturbance and elevation effects on tree and stand growth response of primary Picea abies forest to climate. For . Ecol . Manag ., 354, 77-86.

41. Reich, P.B., Wright, I. J., Cavender-Bares, J., Craine, J. M., Oleksyn, J., Westoby, M. et al. (2003). The evolution of plant functional variation: traits, spectra, and strategies. Int. J. Plant Sci., 164, S143-S164.

42. Rollinson, C.R., Kaye, M.W. \& Canham, C. D. (2016). Interspecific variation in growth responses to climate and competition of five eastern tree species. Ecology , 97, 1003-1011.

43. Saulnier, M., Schurman, J., Vostarek, O., Rydval, M., Pettit, J., Trotsiuk, et al. (2020). Climatic drivers of Picea growth differ during recruitment and interact with disturbance severity to influence rates of canopy replacement. Agric. For. Meteorol. , 287, 1-15.

44. Schimper, A.F.W. (1888). Die epiphytische vegetation amerikas. No. 2, G. Fischer.

45. Schurman, J.S., Babst, F., Björklund, J., Rydval, M., Bače, R., Čada, V. et al. (2019). The climatic drivers of primary Piceaforest growth along the Carpathian arc are changing under rising temperatures. Glob. Change Biol. , 25, 3136-3150.

46. Schurman, J.S., Trotsiuk, V., Bače, R., Čada, V., Fraver, S., Janda, P. et al. (2018). Large-scale disturbance legacies and the climate sensitivity of primary Picea abies forests. Glob. Change Biol. , 24, 2169-2181.

47. Shestakova, T.A., Gutiérrez, E., Kirdyanov, A.V., Camarero, J.J., Génova, M., Knorre, A.A. et al. (2016). Forests synchronize their growth in contrasting Eurasian regions in response to climate warming. PNAS , 113, 662-667.

48. Sperry, J.S., Hacke, U.G. \& Pittermann, J. (2006). Size and function in conifer tracheids and angiosperm vessels. Am .J . Bot ., 93, 1490-1500.

49. Spinoni, J., Szalai, S., Szentimrey, T., Lakatos, M., Bihari, Z., Nagy, A. et al. (2015). Climate of the Carpathian Region in the period 1961-2010: climatologies and trends of 10 variables. Int. J. Climatol. , 35, 1322-1341.

50. Svoboda, M., Janda, P., Bače, R., Fraver, S., Nagel, TA, Rejzek, J. et al. (2014). Landscape-level variability in historical disturbance in primary Picea abies mountain forests of the Eastern Carpathians, Romania. J. Veg. Sci. , 25, 386-401.

51. Teets, A., Fraver, S., Weiskittel, A.R. \& Hollinger, D.Y. (2018). Quantifying climate-growth relationships at the stand level in a mature mixed-species conifer forest. Glob. Change Biol. , 24, 3587-3602.

52. Tyree, M.T. \& Ewers, F.W. (1991). The hydraulic architecture of trees and other woody plants. New Phytol ., 119, 345-360.

53. Wardlaw, I.F. (1990). Tansley Review No. 27: The control of carbon partitioning in plants. New Phytol. , 116, 341-381. 
54. Weigel, R., Muffler, L., Klisz, M., Kreyling, J., van der Maaten-Theunissen, M., Wilmking, M., et al. (2018). Winter matters: Sensitivity to winter climate and cold events increases towards the cold distribution margin of European beech (Fagus sylvaticaL.). J. Biogeogr. , 45, 2779-2790.

55. Weiner, J. (1990). Asymmetric competition in plant populations. Trends Ecol. Evo. , 5, 360-364.

56. West, P.W. (1980). Use of diameter increment and basal area increment in tree growth studies. Can. J. For. Res. , 10, 71-77.

57. Yamaguchi, D. K. (1991). A simple method for cross-dating increment cores from living trees. Can. J. For. Res., 21, 414-416.

Table 1. Sampling summary and cores by species

\begin{tabular}{|c|c|c|c|c|}
\hline Forest Type & Stands (n) & Plots (n) & $\begin{array}{l}\text { Elevation Range } \\
(\mathrm{m})\end{array}$ & $\begin{array}{l}\text { Species (n cores: } \\
\text { overstory/understory }\end{array}$ \\
\hline Picea-dominated & 38 & 538 & $1217-1713$ & $\begin{array}{l}\text {-Picea abies } \\
(9295 / 3826)-\text { Pinus } \\
\text { cembra }(38 / 1)-\text { Acer } \\
\text { pseudoplatanus } \\
(15 / 2) \text {-Abies alba } \\
(11 / 3) \text {-Sorbus } \\
\text { occuparia }(10 / 28)\end{array}$ \\
\hline Fagus-dominated & 21 & 276 & $615-1324$ & $\begin{array}{l}\text {-Fagus sylvatica } \\
(6048 / 1068)-\text { Abies } \\
\text { alba }(1106 / 378) \\
\text {-Picea abies } \\
(540 / 131)-\text { Acer } \\
\text { pseudoplatanus } \\
(274 / 16)-\text { Acer } \\
\text { platanoides }(44 / 1) \\
\text {-Fraxinus excelsior } \\
(18 / 0)\end{array}$ \\
\hline
\end{tabular}

Table 2. Effects of tree size, competition status, community composition and geographic position on basal area increment and synchrony.

\begin{tabular}{|c|c|c|c|c|c|c|c|c|}
\hline$B A I$ & Canopy Layer & Canopy Layer & Intercept & Elevation & Latitude & Diversity & Synchrony & ${ }^{*} R_{M M}^{2}$ \\
\hline \multirow[t]{2}{*}{ FAGUS } & Overstory & & 0.18 & -0.25 & 0.00 & -0.03 & 0.43 & 0.75 \\
\hline & Understory & & -1.08 & -0.08 & 0.14 & 0.05 & 0.15 & \\
\hline \multirow[t]{2}{*}{ PICEA } & Overstory & & 0.34 & -0.12 & -0.08 & 0.01 & 0.17 & 0.49 \\
\hline & Understory & & -0.77 & -0.08 & -0.04 & -0.13 & 0.14 & \\
\hline \multicolumn{9}{|l|}{ Synchrony } \\
\hline \multirow[t]{2}{*}{ FAGUS } & Overstory & & 0.15 & 0.31 & 0.12 & 0.05 & & 0.69 \\
\hline & Understory & & -0.91 & 0.39 & 0.27 & 0.17 & & \\
\hline \multirow[t]{2}{*}{ PICEA } & Overstory & & 0.24 & 0.23 & 0.20 & -0.09 & & 0.78 \\
\hline & Understory & & -0.58 & 0.11 & 0.15 & -0.06 & & \\
\hline
\end{tabular}

$* \mathrm{R}^{2} \mathrm{MM}$ is an $\mathrm{R}^{2}$ approximation for mixed-effects models proposed by (Nakagawa and Schielzeth 2013)

Table 3. Standardized effect sizes of stand structure, community composition and geographic position on mean basal area increments and mean interseries correlations $(r)$ 
within forest inventory plots

\begin{tabular}{lllllll}
\hline BAI & & & Synchrony $(\mathbf{r})$ & & \\
Variable & Effect & $P$ & Variable & Effect & $P$ \\
Intercept & 0 & 0.93 & Intercept & 0.04 & $<0.001$ \\
Elevation & -0.33 & $<0.001$ & Elevation & 0.42 & $<0.001$ \\
Latitude & -0.02 & 0.47 & Latitude & 0.27 & $<0.001$ \\
Elevation*Latitude & -0.1 & 0.12 & Elevation*Latitude & 0.15 & $<0.001$ \\
Diversity & -0.02 & 0.53 & Diversity & -0.44 & $<0.001$ \\
Basal Area & 0.24 & 0.01 & Basal Area & 0.1 & $<0.001$ \\
Density & -0.35 & $<0.001$ & Density & -0.14 & $<0.001$ \\
Severity of recent disturbance & 0.12 & $<0.001$ & Severity of max. disturbance & 0.04 & 0.08 \\
Time since recent disturbance & -0.23 & $<0.001$ & Time since max. disturbance & 0.18 & $<0.001$ \\
Synchrony & -0.24 & $<0.001$ & & & \\
$\mathrm{R}^{2}$ & 0.42 & $\mathrm{df}=783$ & & 0.59 & $\mathrm{df}=784$ \\
\hline
\end{tabular}
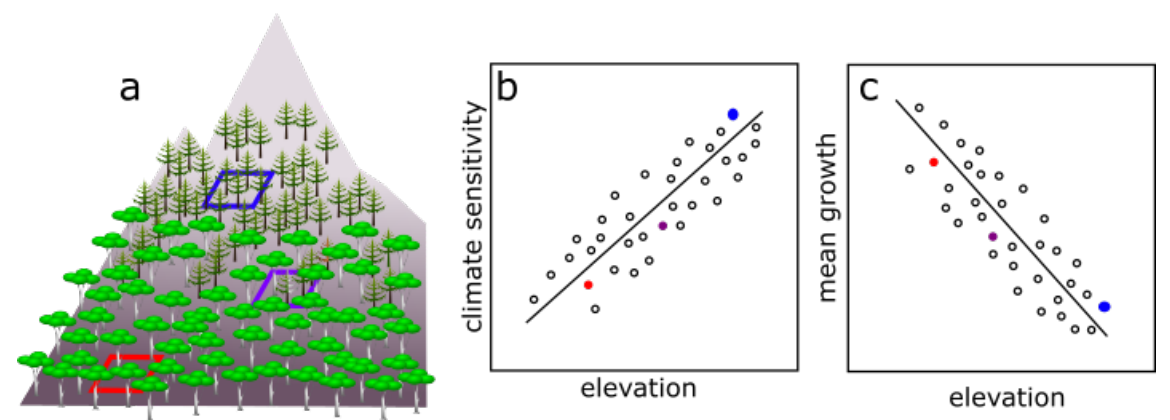

d
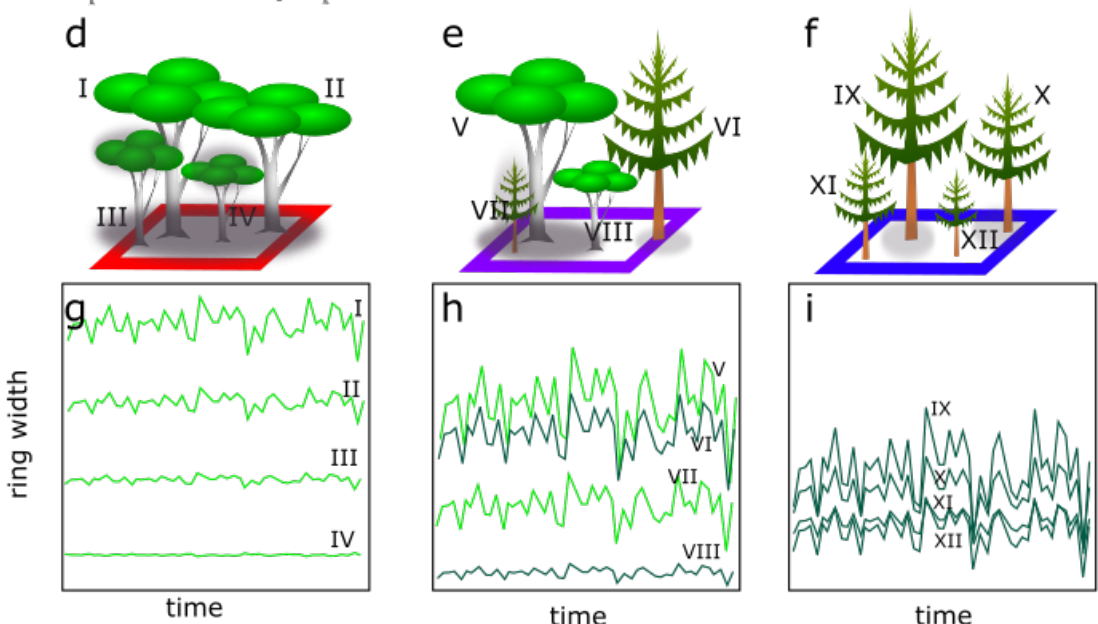

elevation

Figure 1. Predicted tree growth patterns along a temperature limitation gradient. Deciduous angiosperms and evergreen conifers are classically distributed along temperate to alpine forest transitions (a). The climate sensitivity of tree growth increases towards upper elevations (b) and mean tree growth rates decline (c). Panels $d, e, f$ depict community composition in core and edge habitats of Fagus and Picea. Panels $g, h$, $i$ depict 
associated growth time series of individuals marked with corresponding Roman numerals. At low elevations $(d, g)$, high variation in growth rates and low correlation among growth series results from competition. At high altitudes $(f, i)$, we predict lower variation in growth and high synchronization due to climate stress. At mid elevation sites where life-histories overlap, we expect increased growth synchrony of Fagus, including less severe competitive interactions under interspecific competition. For Picea, we predict an increase in maximum growth rates, but comparatively greater competitive suppression of understory individuals under interspecific competition compared to Fagus.

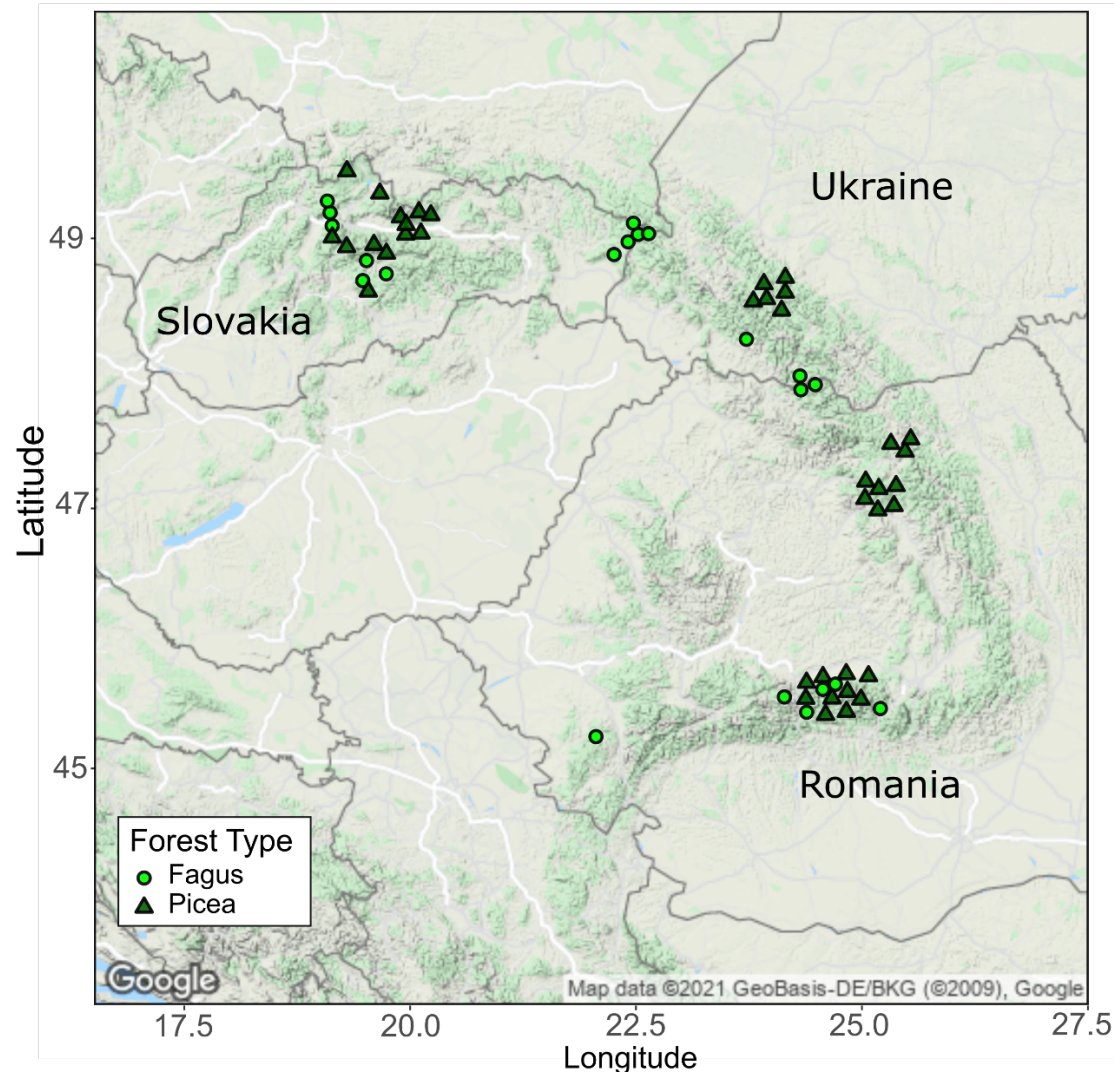

Figure 2. Study sites throughout the Carpathian Mountains. Symbols indicate the locations of primary forest fragments, which are further subsampled with a stratified random design of forest inventory plots. Circles indicate Fagus dominated fragments, and triangles indicate Picea dominated fragments. Symbols are slightly offset from precise coordinates to reduce overpotting. Map created using ggmap (Kahle and Wickham 2013). 

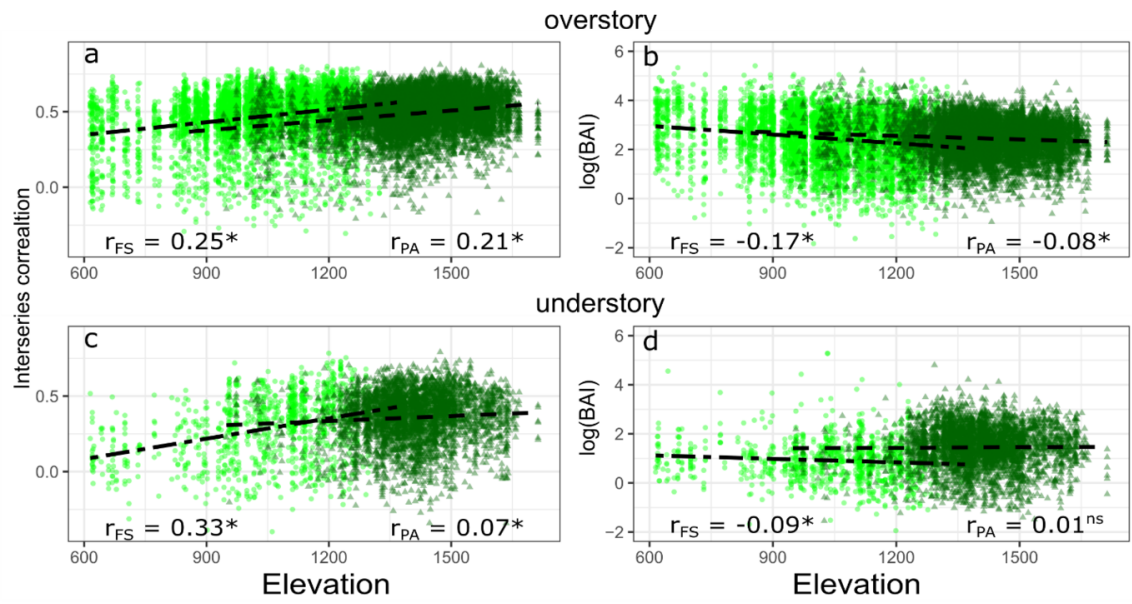

$$
\text { understory }
$$
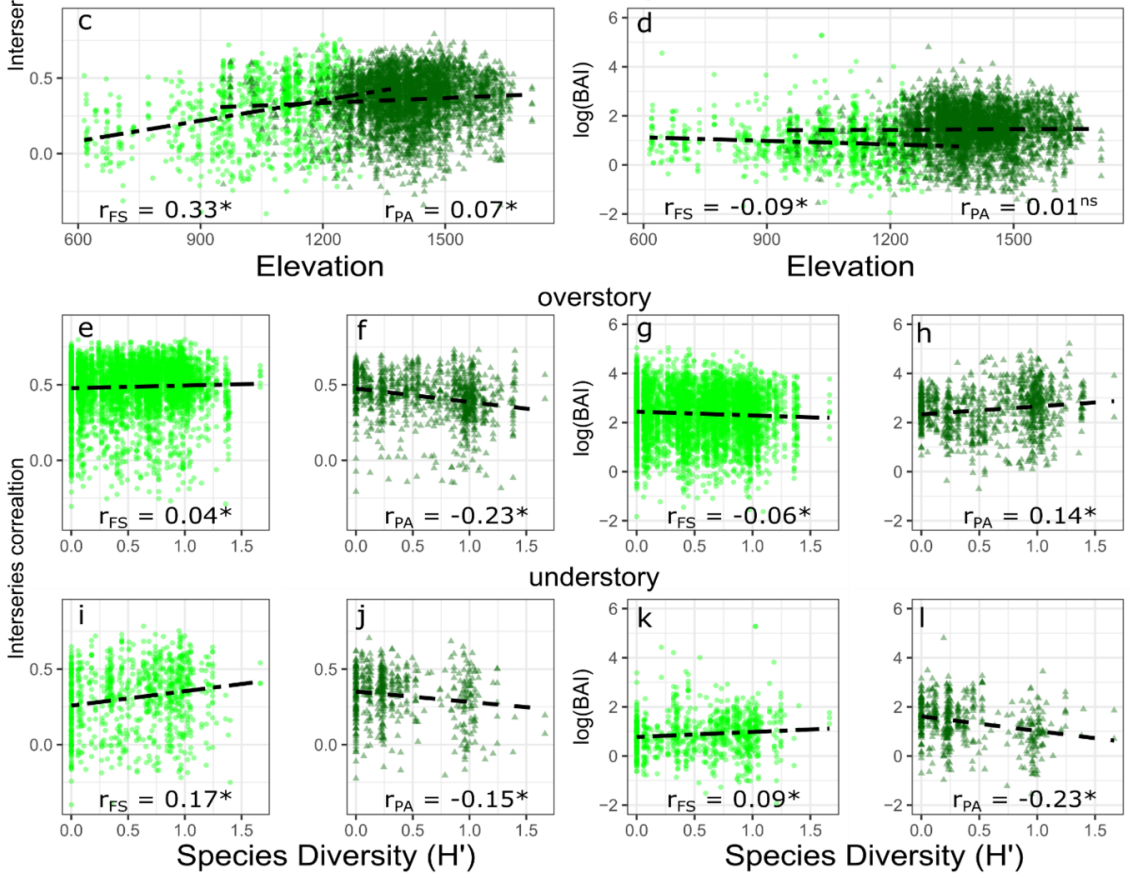

Figure 3. Bivariate relationships between interseries correlations and basal area increments as a function of elevation and community composition. Coefficients represent correlation estimates and significant relationships are indicated with an asterisk $\left(^{*}\right)$. Rows 1 and $3(a, b, e, f, g, h)$ show patterns for overstory trees. Rows 2 and $4(c, d, i, j, k, l)$ show patterns for understory trees. Dark triangles represent Picea abies, Light circles represent Fagus sylvatica. 

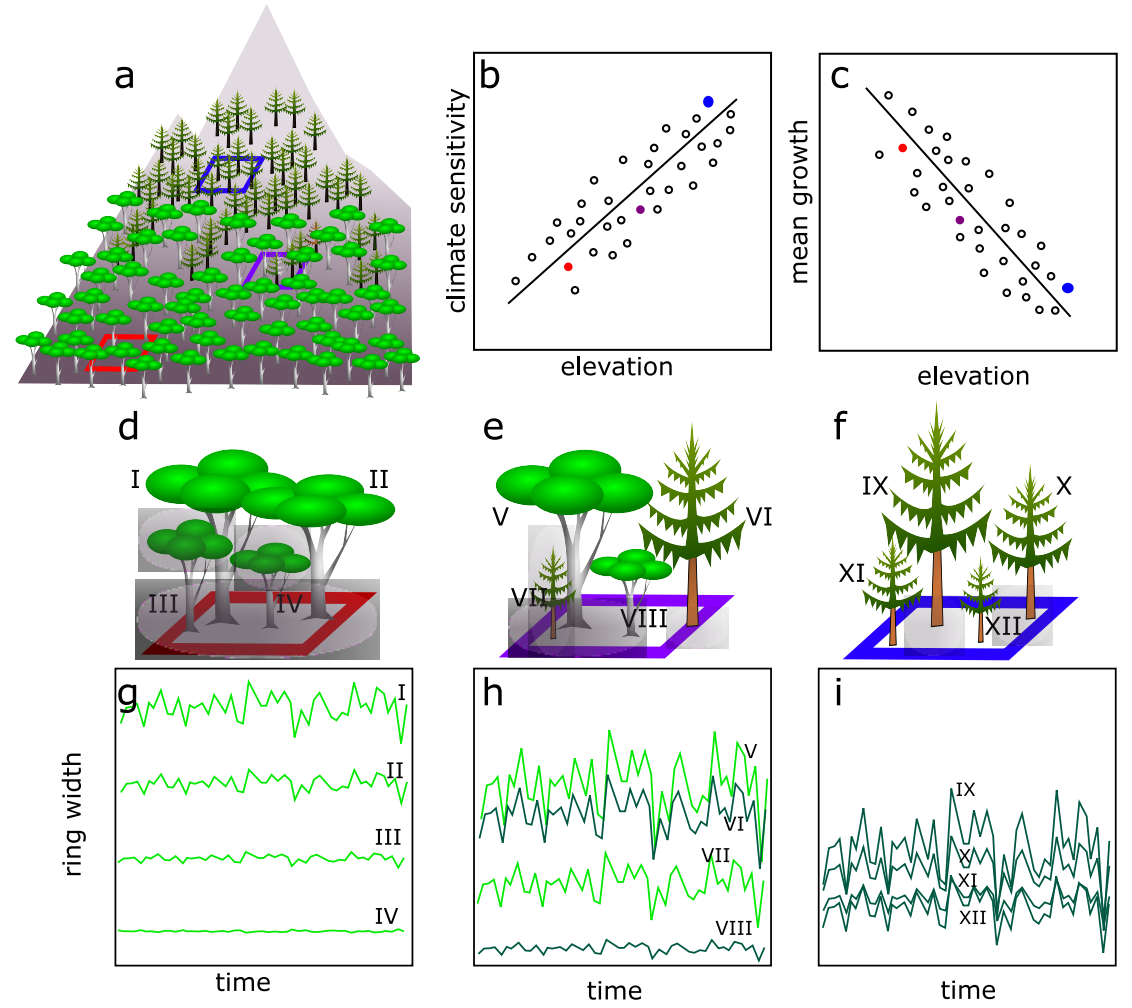

elevation 


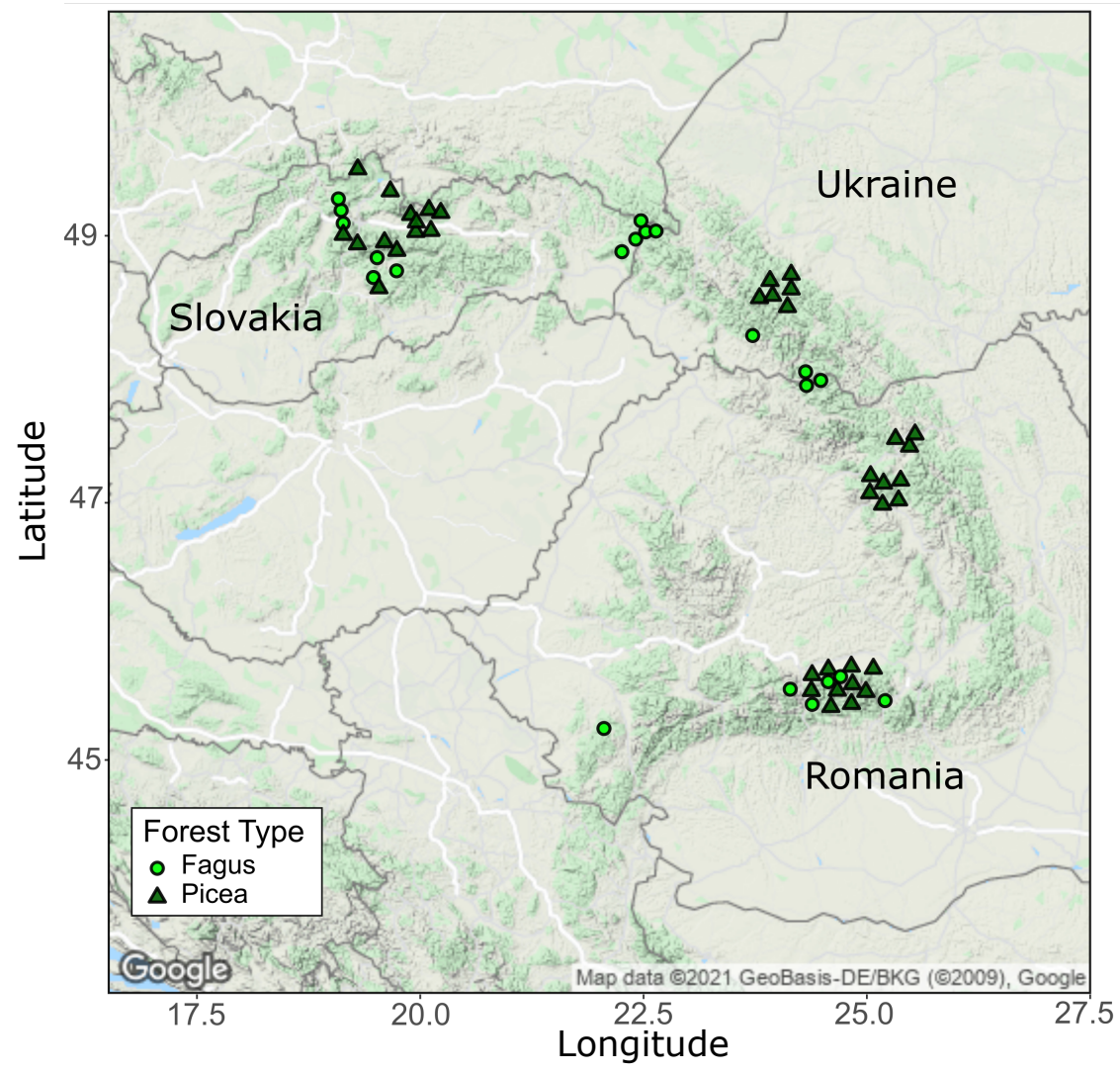



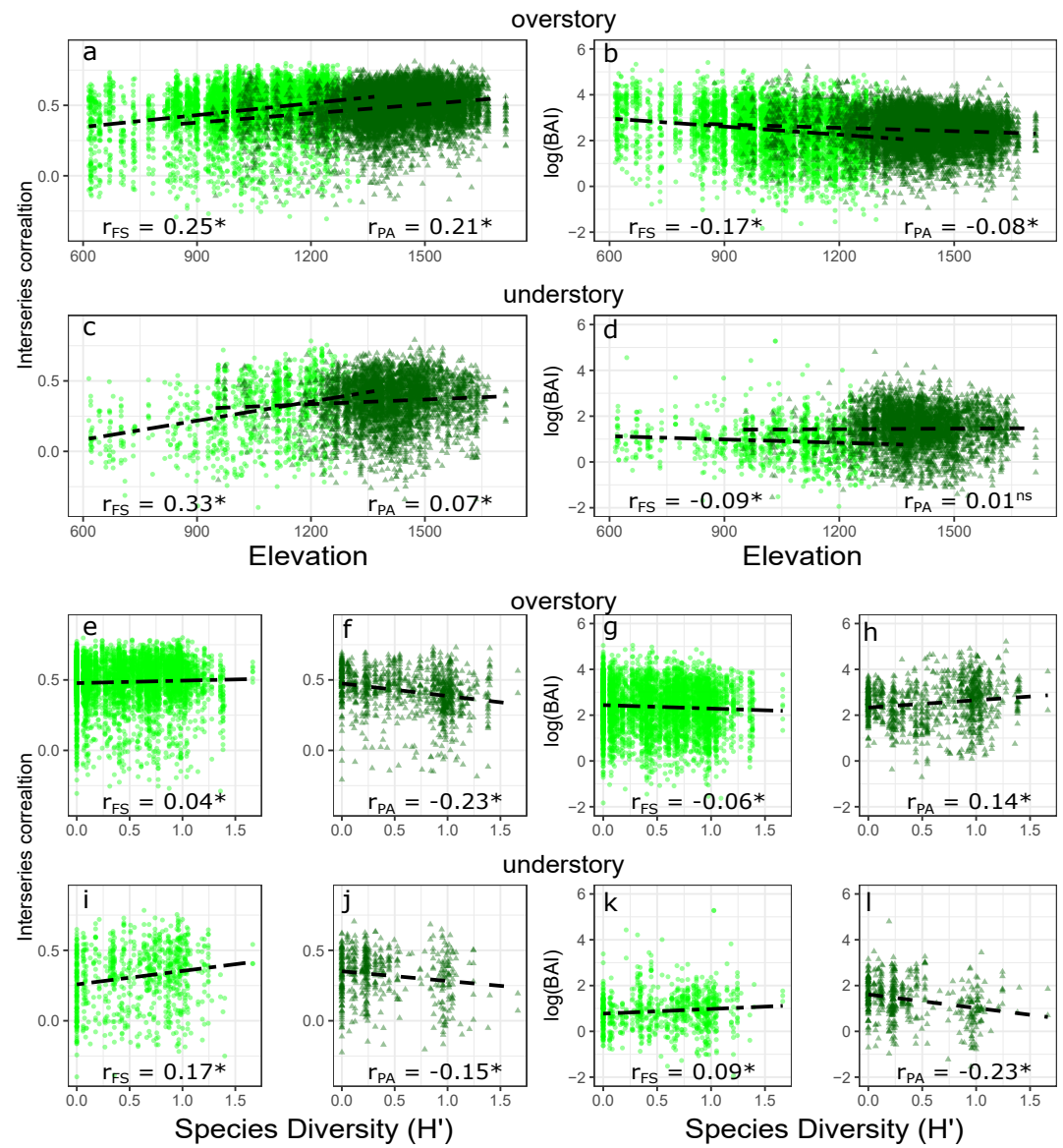